\title{
Teoría y práctica de las reformas en los sistemas de salud: los casos de Brasil y México
}

\author{
Theory and practice in health systems \\ reform in Brazil and Mexico
}

Raquel Abrantes Pêgo 1

Celia Almei da 2

1 Centro de Investigación de Sistemas de Salud, Instituto Nacional de Salud Pública. Av. Universidad 655, Cuernavaca, Morelos 62508, México. rpego@correo.insp.mx 2 Departamento de Administração e Planejamento em Saúde, Escola Nacional de Saúde Pública, Fundação Oswaldo Cruz. Rua Leopoldo Bulhões 1480, Rio de Janeiro, RJ 21041-210, Brasil. calmeida@ensp.fiocruz.br
Abstract This study focuses on the role of public heal th experts in the contemporary health sector reform process. The authors discuss the issue based on the case of Brazil and Mexico, where a group of public health specialists have oriented their participation to influence the conflict concerning health policy reform in the respective countries. One approach has been to devel op a new cognitive framework for technical health sector reform projects viewed as policy proposals with technical content. The purpose is to demonstrate how these specialists have managed to influence the national debate over heal th sector reform when the technical and scientific discussi on leaves the academic sphere and reaches the social and political realm. The authors contend that this occurs because such technical and scientific knowledge has been postulated (independently of its intrinsic value) as a political and ideological alternative platform for sustaining a health sector reform proposal which, once transformed into a policy project, has served to aggre gate certain political and social forces.

Key words Equity; Health Sector Reform; Health System; Health Care Reform

Resumen Este trabajo se propone reflexionar sobre el lugar quela comunidad de los especialistas en salud pública está ocu pando en las reformas contemporáneas de los si stemas de salud. Discutimos la cuestión a partir de los casos de Brasil y de México porque, en ambos países, un grupo de especialistas en salud pública proyectó su participación más allá del ámbito técnicocientífico y logró influir en el conflicto en torno a la reorientación de las políticas de salud de sus países. Una de sus acciones consi stió en elaborar un marco cognoscitivo en el cual se alimentan proyectos técni co-asi stenciales de reforma entendi dos como propuestas políticas con contenido técnico. Nuestro propósito es demonstrar que estos profesi onales logran influir en el debate nacional en el momento en que la discusión técnico-científica rebasa el ámbito de los especialistas para instalarse en el palco del debate socio-político. En nuestra opinión, esto sucede porque el conocimiento técni co-científico producido por esos grupos fue postulado, independendiente de su valor intrínseco, como plataforma ideológica alternativa, capaz de dar sustento a un proyecto técni co-asistencial de referencia que, convertido en proyecto político, sirvió para agl utinar a determinados sectores sociales.

Palabras clave Equidad; Reforma del Sector Salud; Sistema de Salud; Reform en Atención de la Salud 


\section{Introducción}

Este trabajo se propone reflexionar sobre el lugar que la comunidad de los especialistas está ocupando en las reformas contemporáneas de los sistemas de salud. Discutimos la cuestión a partir de los caso de Brasil y de México porque, en ambos países, los investigadores en salud pública, como especialistas, proyectaron su participación para allá del ámbito técnico-científico, logrando influir en el conflicto en torno a la reorientación de las políticas de salud de sus respectivos países. Una de sus acciones consistió en elaborar un marco cognoscitivo con el cual alimentar proyectos técnico-asistenciales de reforma que servieron de plataforma políticoideológica para determinados grupos sociales.

En el caso de Brasil, a partir de los años 70, un grupo de médicos-sanitaristas, en su mayoría simpatizantes de la izquierda comunista y socialista, algunos con vinculación políticopartidaria, construyó su identidad en torno del concepto de salud colectiva. Sus integrantes fueron protagonistas principales del “Movimiento de la Reforma Sanitaria" en la década siguiente (pari passu a la transición democrática) y se organizaron en el Centro Brasileño de Estudios de la Salud (CEBES - creado en 1976) y en la Asociación Brasileña de Postgrado en Salud Colectiva (ABRASCO - creada en 1979). Como grupo técnico-científico, se oponían a la salud pública tradicional y lucharon por el control de sus espacios institucionales de reproducción y de formación de recursos humanos. Ese grupo fue un firme opositor de la política de salud del régimen militar y, con la llegada de la Nueva República (en 1985), sus miembros ocuparon importantes cargos en los distintos niveles del poder ejecutivo (federal, estatal y municipal), desde donde lograron institucionalizar un Sistema Único de Salud (SUS).

En el caso de México, en respuesta al contexto de cambio económico-político que emergió con el gobierno De la Madrid (1982-1988), un grupo de médicos-sanitaristas, algunos vinculados al Partido Revolucionario Institucional (PRI) y otros independientes, propuso una Nueva Salud Pública en oposición a las concepciones existentes en práctica tanto en las instituciones formadoras de recursos humanos para el sector como en las de asistencia. Dicho grupo encabezó simultáneamente la creación de una organización estratégica, la Fundación Mexicana para la Salud (FU NSALUD - creada en 1985) y emprendió una lucha por controlar tanto las instituciones formadoras de recursos humanos en salud pública, creando el Instituto Nacional de Salud Pública (INSP), vinculado a la Secretaría de Salud, cuanto las instituciones públicas de salud y ocupando cargos de dirección en el área.

Algunas cuestiones estaban en el núcleo del esfuerzo de movilización de ambos grupos. En el caso de Brasil, estos especialistas consideraban que la política de salud promovida por el régimen militar, al lado de una gestión tecnocrático-autoritaria, buscaba privilegiar la privatización y la medicalización de los problemas sociales, menospreciando la salud pública. Para eso, según esa visión, durante el régimen militar se había implementado la extensión de la cobertura de la atención médica sin expandir la red pública, promoviendo la organización de las empresas médicas privadas, y subsidiando el crecimiento del sector médicohospitalar privado, contratado como proveedor por el Estado. La asistencia médica de la Previdencia Social era autónoma, separada del Ministerio de Salud (MS), y dominaba el sector. Este modelo había profundizado las desigualdades y fortalecido un sistema de salud dual y fragmentado, con una estructura centralizada. Además, la escasa participación de los sectores sociales organizados en la determinación de las políticas sectoriales y en el control del uso de los recursos agravaba esas tendencias. También denunciaban que había aumentado la demanda no satisfecha por servicios de salud, pari passu al empeoramiento de las condiciones de vida de las poblaciones, las epidemias sucedían y resurgían algunas de las enfermedades infecciosas anteriormente controladas.

En contra de eso, y de los interventores del régimen militar, en sus locales de trabajo y en asociaciones de representación, estos médicos y otros profesionales vinculados a la salud pública se organizaron en torno al compromiso de producir un nuevo conocimiento que sirviera a las causas populares y fuera capaz de materializar una propuesta alternativa de política de salud, basada en el principio de la salud como un derecho de ciudadanía. Ese grupo logró transformar sus ideas en un proyecto técnicoasistencial, desarrollar estrategias que aglutinaran fuerzas políticas alrededor de un ideario de reforma y conformar un bloque de presión en el ámbito de la Asamblea Nacional Constituyente (1987-1988) (Brasil, 1998). Eso permitió la inscripción de ese derecho en la nueva constitución, redactada en 1988, particularmente en el artículo 196, donde se lee que “la salud es derecho de todos y deber del Estado, garantizado mediante (...) el acceso uni versal eigualitario a los servicios desalud".

En México, algunos jóvenes médicos, especialistas en Salud Pública, creían que su país 
necesitaba un sistema de salud moderno, ágil, menos politizado y estatizado, con una ciudadanía más responsable con relación a su salud y con una mayor participación del sector privado. Dicho sistema debería ser capaz de responder al complejo cuadro epidemiológico caracterizado por la fuerte presencia de enfermedades crónico-degenerativas, acompañadas por padecimientos propios de un cuadro de pobreza extendida. Todo esto en un contexto marcado, según ellos, por la escasez de recursos y por una creciente demanda, no satisfecha, por servicios de salud en el país, y por un sistema de atención a la salud, consolidado entre 1940-1970 en una estructura centralizada y dual - seguridad social y salubridad y asistencia -, permeado por intereses corporativos y de clientelas, que ya no respondía a las necesidades de una economía globalizada. Al mismo tiempo, et pour cause, su desempeño fue caracterizado por siete "ins": inequidad, insuficiencia de recursos, ineficiencia, inadecuada calidad, insatisfacción de los usuarios, inflación, e inseguridad. Estos médicos sanitaristas, congregados en torno del doctor Guillermo Soberón, estaban convencidos de la necesidad de iniciar un diálogo sobre las prioridades del sistema de salud en México. De acuerdo con ellos, era urgente introducir cambios en el proceso de decisiones para incrementar la calidad, el acceso, la equidad, y la libre elección de servicios por parte del consumidor. Ellos estaban dispuestos a revertir la tendencia que favorecía los intereses corporativos en nombre de la libre competencia de forma a garantizar un uso más racional y efectivo de los recursos.

Este último punto lleva a la segunda cuestión que movilizaba al grupo. Desde la década de los setenta, algunos segmentos de la sociedad mexicana venían poniendo en tela de juicio el sistema de partido único, y el corporativismo como la forma legítima de intermediación de los intereses, y planteando la necesidad de una sociedad civil más actuante e independente del Estado, como también fue planteada una mayor participación del sector privado en la condución de los rumbos de la sociedad. Fue en consonancia con esa visión que el grupo creó FUNSALUD en 1985, una institución que desde entonces ha tenido un papel importante en el sector salud, y que logró, entre otras cosas, plasmar su propuesta en el programa de reforma del gobierno del presidente Ernesto Zedillo (1994-2000).

¿Por qué la salud pública tradicional fue atacada por ambos grupos? ¿Cuáles eran las características fundamentales de la salud colectiva y de la nueva salud pública, formuladas como campos técnico-científicos inovadores? ¿Qué les permitió crecer y cambiar el debate sectorial? ¿Cuáles han sido las estrategias de esos dos grupos para influir en las agendas de la reforma del sector salud en sus respectivos países? Y, por último, ¿qué lecciones se pueden aprender de la actuación y contribución de estos dos grupos de especialistas para las reformas en proceso en ambos países?

Este artículo tratará de responder a esas preguntas, examinando algunos de los factores que, a nuestro juicio, confluyeron para dotar a esos grupos de la fuerza necesaria para intervenir con éxito en el debate nacional. Para eso, expondremos cada caso por separado, mostrando en primer término el surgimiento de las respectivas corrientes de pensamiento en el campo de la Salud Pública, en torno a las cuales se organizan y consolidan nuevas perspectivas técnico-científicas. Enseguida demostraremos sus articulaciones con fuerzas políticas y sociales, y analizaremos la conversión en vertientes de lucha al interior de las instituciones de salud para impulsar cambios y controlar el futuro del sector. Nuestro propósito es demonstrar que estos especial istas lograron influir en el debate nacional en el momento en que la discusión técnico-científica rebasa el ámbito profesional para instalarse en el palco del debate socio-político. En nuestra opinión, esto sucede porque el conocimiento técnico-científico producido por esos grupos fue postulado, independiente de su valor intrínseco, como una plataforma ideológica alternativa, capaz de dar sustento a un proyecto técnico-asistencial de referencia que, convertido en proyecto político, sirvió para aglutinar a determinados sectores sociales y no a otros.

El concepto de salud colectiva y el movimiento de reforma sanitaria en Brasil

La construcción de un proyecto alternativo de reforma del sistema de salud en Brasil tiene antecedentes en los años setenta, aún en la época de la dictadura militar, y está articulada a la intensa transformación de la sociedad brasileña, principal mente durante los años ochenta, cuando el modelo de relaciones entre el Estado y la sociedad comenzó a ser duramente criticado, sobre todo en el área social. Son los años en que la enorme deuda social acumulada durante el régimen militar pasó a ser cobrada.

El padrón de intervención del Estado brasileño en el área social se remonta a las décadas de 1920 y 1930, cuando los derechos sociales y de ciudadanía fueron vinculados al lugar del individuo en el mercado formal de trabajo a 
través de un sistema de seguridad social organizado por categorías profesionales en los Institutos de Jubilación y Pensiones que ofrecían asistencia médica diferenciada con coberturas desiguales. La atención a los grupos excluidos del proceso de desarrollo económico y las acciones de saneamiento fueron respondidas por el MS. El golpe militar de 1964 no sólo implicó la exclusión de la participación de los sindicatos del proceso de toma de decisión sectorial, reforzando una visión tecnócrata, como, además, desencadenó una reforma institucional y administrativa de grandes proporciones: unificó los Institutos de Jubilación y Pensiones (1966) y, en la década seguiente, creó el Sistema Nacional de Previdencia Social (1977), donde se insertaba la principal institución de servicios médicos, el Instituto Nacional de Asistencia Médica de la Previdencia Social (INAM PS). A partir de entonces, se retiró defacto del MS el poder de formulación de la política de salud. El resultado fue el predominio de la atención médica como modelo asistencial y como volumen de recursos. Para eso, los gobiernos militares combinaron una fuerte intervención del Estado como financiador y comprador de servicios al sector privado y el favoritismo de la asistencia hospitalaria en detrimento de la atención básica, de la preventiva y de la salud pública.

Fue en contra de esa política que a mediados de los anõs setenta comenzó a delinearse un grupo, compuesto en su mayoría de médicos-sanitaristas militantes en la izquierda comunista y socialista, algunos filiados al Partido Comunista Brasileiro. Ese grupo tenía su sede en algunos departamentos de medicina preventiva, institutos universitarios o de investigación, e instituciones de servicios. Desde allí, con base en una perspectiva médico-social y con el apoyo de sectores de la Organización Panamericana de la Salud (OPS), inició la lucha por la hegemonía al interior del propio "preventivismo", oponiéndose tanto a los sanitaristas tradicionales, ubicados en al gunos grupos de la academia y en sectores de la tecno-burocracia de las instituciones públicas del área de la salud, como a los "racionalizadores", presentes en el MS, y a los privatistas que estaban principalmente en las instituciones de seguridad social. Esos profesionales se oponían a la salud pública tradicional y a las propuestas de cambio elaboradas exclusivamente a partir del marco biomédico, bien como discutían de forma crítica las orientaciones difundidas por los organismos internacionales, como la Organización Mundial de la Salud (OMS).

Esa oposición planteó desde el inicio la necesidad de "unidad" no sólo teórica, sino fun- damentalmente político-ideológica, y tomó cuerpo a través de la propuesta de construcción de un proyecto que se enfrentaba a la dictadura desde el área de la salud. El concepto de Salud Colectiva fue entonces formulado con el propósito de institucionalizar un campo de conocimiento específico y una nueva vertiente analítica. Se constituyó de la negación de la práctica médica hegemónica, identificada como operadora de un modelo indeseable de atención a la salud, y de la oposición a la práctica tradicional de la salud pública, por sus insuficiencias y su subordinación a la perspectiva médica (Birman, 1991). Al mismo tiempo, la práctica política de ese grupo postulante de la Salud Colectiva (que Ilamaremos a partir de ahora de sanitaristas-colectivistas) reclamaba la "transformación social" y, para eso, abogaba por la constitución de un sujeto dotado de "conciencia social", conquistada a través de su “conciencia sanitaria” (Escorel, 1987, 1998; Teixeira, 1987).

En ese sentido, esa vertiente de análisis buscará "distinguirse de las anteriores (por) su producción teórica centrada en lo social como determinante de las condiciones de salud, como también por apuntar hacia la necesidad práctica del sanitarista como sujeto político de la transformación pretendida" (Escorel, 1987:9596). El adjetivo "colectivo" fue introducido para definir el objeto que se procuraba comprender y sobre el cual se quería intervenir - la dimensión social de la enfermedad (por oposición a la individual), y el método de aproximación elegido fue el "histórico-estructural" (por oposición a los abordajes funcionalistas y fenomenológicos utilizados en las décadas precedentes) (Nunes, 1985). La producción de conocimiento a que nos referimos nació, pues, como un "saber militante" (Cohn, 1989:124), como una especie de base ideológica para una militancia política transferida al área profesional. En un primer momento, esa militancia se orientó por el primado de lo social sobre lo biológico, como eje determinante de la problemática vinculada a la cuestión de la salud; posteriormente, predominó la subordinación de todos los ámbitos de la reflexión a lo político.

En su eje conceptual, la noción de salud colectiva se sitúa en un dominio donde confluyen varias áreas del conocimiento que trabajan con diferentes objetos. Ella buscó representar una inflexión decisiva para el concepto de salud, ya que, por un lado, niega el universalismo naturalista del saber médico, aceptando otras lecturas y prácticas de curación, lo que provoca una ruptura con los discursos biológicos y con la concepción clásica de salud pública, domi- 
nantes en el campo de la salud. Por otro lado, promueve la reestructuración del propio campo de la salud pública, dado el énfasis que atribuye a la dimensión histórica de la enfermedad, y a la práctica política como transformadora de lo social. Con la noción aludida se replantea también el lugar del público, que no es más visto como "estatal", opuesto a lo "privado", sino en términos del espacio de expresión, enfrentamiento y negociación de demandas, ya sean ellas individuales o colectivas (Birman, 1991).

Para llevar adelante su lucha política y en consonancia con la gran movilización de la sociedad civil en contra del régimen militar, se creó, en 1976, el CEBES. Debido a su acción organizativa y de movilización, logró congregar médicos, salubristas, líderes sindicales del área de salud, mujeres feministas y otros profesionales involucrados en los diversos movimientos de oposición sectorial. Fundaron la revista Saúde em Debate, y promovieron debates, discusiones, apoyos a las demandas de los movimientos populares y participaron de las diversas manifestaciones en contra de los militares y de sus políticas de salud. EI CEBES dio gran importancia a la gestión de propuestas alternativas de políticas de salud y a la formulación de estrategias para su puesta en práctica. También fue creado en el ámbito académico la ABRASCO, en 1979, para el diseño de políticas tendientes a la formación de recursos humanos, y de análisis crítico del modelo vigente de asistencia a la salud, así como de generación y difusión de las propuestas de reforma (Teixeira \& Mendonça, 1989).

En inicios de la década de los ochenta, la salud colectiva como una propuesta de ámbito académico había consolidado junto a los organismos públicos de conducción de la política científica y educativa, con financiamientos propios, diferente tanto de las disciplinas médicas correlativas como de la salud pública tradicional. Se reestructuraron y organizaron postgrados de acuerdo con la perspectiva de la salud colectiva, como también innumeras investigaciones fueron financiadas con apoyo de los organismos científicos nacionales e internacionales. También forneció cuadros a los organismos internacionales sectoriales y promovió un intercambio de experiencias e ideas con los países latinoamericanos y con el continente europeo, en particular con Italia y España, debido a que tenían propuestas semejantes de reforma sanitaria y en particular con el representante del entonces Partido Comunista Italiano, Giovanni Berlinguer.

Otro resultado de esa dinámica fue el surgimiento de una propuesta alternativa de orga- nización de los servicios de salud. Una parte importante de esas propuestas centró su atención en los planos jurídico-legal y administrativo-organizacional de la organización médica. En ella, la práctica clínica hegemónica, o su expresión organizacional - la asistencia médica -, fue analizada mayoritariamente dentro de este último plano. De forma simultánea, grupos específicos dentro de esta corriente buscaron descubrir las veredas tortuosas por las cuales podría darse la transformación de las necesidades sentidas en demanda social, investigando los Ilamados "nuevos movimientos sociales en salud" y sus pautas de demanda. La participación de los ciudadanos fue incorporada como elemento importante para la democratización de la salud. Aun negaban que las necesidades de salud encontraran en el campo médico su área privilegiada de expresión. El punto de referencia principal para la delimitación del proyecto técnico-asistencial de los sanitaristas-colectivistas fue el hecho de que "la generalización del consumo médico no se haya puesto al alcance de todos los grupos sociales, y de que persistieran modalidades aún relativamente excluyentes de producción de servicios de salud" (Donnangelo, 1975:76). En resumen, los postulados básicos que constituyeron la salud colectiva se fueron perfilando en oposición a la dictadura militar y se afirmaron a la sombra del proceso de transición política, como una modalidad específica del discurso sanitarista, con fundamento epistemológico y registro histórico y conceptual propios, al mismo tiempo en que se planteaba un proyecto político-ideológico profesional militante de reforma sanitaria, vehiculado por el Ilamado “Movimiento Sanitario", que analizaremos enseguida.

\section{La salud colectiva, el proyecto político de la reforma sanitaria y la actuación de los salubristas-colectivistas}

Alentado por el contexto de la transición brasileña, y resultado de la confluencia de diversas fuerzas sociales y políticas comprometidas con el proceso de democratización de la sociedad y con la mejoría de las condiciones de vida y salud de los diversos grupos sociales, surgió en inicios de los años ochenta el "Movimiento por la Reforma Sanitaria Brasileña”. Fue conformado y dirigido por la militancia profesional de oposición en el sector, y alimentado tanto por las luchas corporativas profesionales como por la reactivación de los partidos políticos y de la organización de diversos sectores sociales, y logró, en un primer momento, "unificar" una posición sectorial global contra la política de 
salud puesta en práctica por el gobierno autoritario. El movimiento alcanzó mayor visibilidad en las postrimerías del régimen militar, cuando los sanitaristas que componían su liderazgo pasaron a ocupar la dirección de importantes instituciones sectoriales.

También fueron determinantes para la expansión del movimiento de reforma sanitaria las diversas manifestaciones de insatisfacción con la política de asistencia médica que se produjeron en diferentes momentos a partir de la segunda mitad de la década de los setenta. Dicha insatisfacción se materializó en la destrucción de ambulatorios médicos y en el estallido de protestas espontáneas de derechohabientes y de la población no asegurada en las largas colas de los servicios médicos, en el surgimiento de asociaciones populares comunitarias, de vecinos y de mujeres en torno a cuestiones concretas de salud de estos conjuntos sociales; en organizaciones de enfermos "marginalizados" (como los hansenianos), en huelgas de profesionales de salud. De forma simultánea, se desencadenó un proceso en el que varias organizaciones (como la I glesia Católica, los sindicatos y otras asociaciones de la sociedad civil) y partidos políticos progresistas denunciaban la situación caótica de la atención a la salud de la población (Luz, 1991).

En el plano del desarrollo socio-político del movimiento, se delineó un embate políticoideológico dentro del propio campo de la salud colectiva, que reflejaba no sólo los cambios generales que se encontraban en proceso en la sociedad, sino también los diferentes proyectos políticos en gestación. Así, para los salubristas-colectivistas, la reformulación del sistema de salud, vista en el contexto del cuadro político que se diseñaba, hacía parte del proceso de construcción de la democracia. Sin embargo, divergían entre ellos sobre la mejor estrategia para alcanzar esa reformulación. Algunos, en particular el grupo más próximo al partido comunista, privilegiaban el ámbito institucional, defendiendo el "control del aparato burocrático estatal" en sus diversos niveles gubernamentales. Otros, en particular la izquierda no comunista, daban preferencia al ámbito societario, defendiendo el refuerzo de la sociedad civil. Para ambas perspectivas era importante denunciar el compromiso histórico de la burocracia de las instituciones de seguridad social con los intereses del sector privado, la corrupción reinante, las pésimas condiciones de las instituciones públicas de salud y el desprecio por la salud pública. En términos concretos, las distintas visiones en torno de la construcción de un sistema democrático y ciudada- no significaron dos estrategias principales de lucha y alianzas diversas, pero sí complementarias.

Los adeptos al refuerzo de la sociedad civil inclinaron al apoyo y a la colaboración con los movimientos reivindicatorios en pro de mejores condiciones de vida y salud, protagonizados por moradores de la periferia de las grandes ciudades, así como con los movimientos de mujeres. Promovieron experiencias alternativas en áreas urbanas y rurales con el apoyo de otros sectores de la sociedad, como la I glesia Católica o los gobiernos locales de oposición, en particular aquellos vinculados al Partido del Movimiento Democrático Brasileño (PMDB). Los “institucionalistas”, toda vez que se postulaba que era a través del Estado que se podrían crear las condiciones para el ejercicio de la ciudadanía, desplazaron su lucha hacia dentro del aparato de Estado - actuando como si fueron un partido político (el "partido sanitario") -, puesto que sería éste "el gran catalizador y articulador de los anhel os de cambio de los diferentes grupos sociales" (Campos, 1988:183). La decisión de "ocupar espacios de poder" (Escorel, 1987, 1998) fue instrumentalizada mediante la ocupación de cargos técnicos en las instituciones del sector capaces de influenciar en la política de salud en los distintos niveles del gobierno. Eso fue posibilitado por una serie de alianzas con segmentos "publicistas" de la tecno-burocracia próximos al partido de la oposición (PMDB).

De esa manera, los sanitaristas-colectivistas lograron convertirse en una vertiente ideológica en las pugnas internas de las instituciones gubernamentales de salud $y$, a través de procesos extremamente conflictivos, aprovecharon de las disputas por la conducción de la política sectorial y de las fisuras presentes entre la tecnoburocracia del MS y la de Seguridad Social, para formular y operar en un primero momento, en la primera institución, proyectos dirigi dos hacia los grupos sociales excluidos de la política de salud. Para eso se valieron de las propuestas de los organismos internacionales y de sus financiamientos, tanto las racionalizadoras como las de extensión de cobertura en salud, de medicina comunitaria y de integración docente-asistencial. Estas propuestas fueron, en su gran mayoría, apropiadas de forma instrumental como un vehículo de promoción de experiencias alternativas de atención, de organización de la población y de una renovación de la salud pública. Entre éstas, podemos citar el programa desarrollado en el Municipio de Paulínia, en São Paulo, por la Faculdade de Ciências Médicas, Universidade Estadual de Campinas (UNICAMP), financiado por la Fun- 
dación Kellogg, y el de Montes Claros, en Minas Gerais, que originalmente era un proyecto piloto de planificación familiar, en una articulación de la Universidad de Tulane (Estados Unidos) y la Universidad del Norte de Minas Gerais, cuyos desdoblamientos lo transformaron en un proyecto de reorganización de servicios, que fue incorporado por la Secretaría Estatal de Salud, y en un marco de referencia para otros proyectos de mudanzas institucionales en los niveles estatal y federal, además de provocar una serie de enfrentamientos con los cuadros tradicionales de la salud pública, en todos Ios niveles (Escorel, 1987, 1998; Muller Neto, 1989, 1991a, 1991b).

Con esas experiencias, Ios sanitaristas-colectivistas marcaron su presencia en el sector y ampliaron el campo de actuación del movimiento reformista, articulándolo con fuerzas políticas municipales en las regiones donde la oposición tenía mayor presencia (Machado, 1988; Muller Neto, 1991a, 1991b; van Stralen, 1998). Para esto fue decisiva la victoria de los candidatos del único partido legal de oposición (el PMDB) en las elecciones municipales de 1976, pues sus gobiernos incorporaron elementos de las experiencias "alternativas" anteriores, y un retiro de los salubristas-colectivistas hacia actividades administrativas de alcance regional. La salud pasó a integrar la agenda política local. Estos eventos trasladaron la "lucha por la reforma" y los conflictos a ella inherentes a los niveles estatales y municipales. Las articulaciones entre las experiencias municipales de cambio comenzaron a ocurrir con la realización de los Encuentros de Secretarios Municipales de Salud, en 1979; y, en 1980, fue creado el Consejo Nacional de Secretarios de Salud (CONASS), como instancia de representación sectorial en los diversos niveles de negociación de la política de salud.

También debido al apoyo del PMDB, los sanitaristas-colectivistas reactivaron los foros sectoriales de discusión, y se amplió el abanico de alianzas en dirección al sector médico-liberal representado en la Seguridad Social. En 1979 se realizó el 1o Simposio sobre Política Nacional de Salud en la Cámara Federal de Diputados y se buscó incrementar y politizar las Conferencias Nacionales de Salud (CNS), instancia tecno-burocrática sectorial que desde 1967 no era convocada. Por contraste, entre 1975 y 1980 fueron realizadas tres conferencias y, en la última, se puso de manifiesto el embate que ya se venía procesando en los bastidores del ámbito burocrático sectorial entre el MS y la Seguridad Social en torno a cómo lograr ampliar el acceso a los servicios de salud.
Todo ese proceso coincide con el descenso del régimen militar a inicios de los años ochenta y con el agravamiento de la crisis financiera de la Seguridad Social. El último gobierno militar responde a la crisis creando un Consejo Nacional de Administración de la Salud de la Seguridad Social (CONASP), en el cual, debido a Ias alianzas con el sector médico-liberal, los salubristas-colectivistas participan y logran negociar la propuesta reformista de integración institucional. El "nuevo modelo asistencial" propuesto por el Plan CONASP tendría como base legal los convenios trilaterales entre los Ministerios de Seguridad Social (Ministério da Previdência e Assistência Social - MPAS), de Salud y las Secretarías Estatales de Salud. A través de ellos se pretendía utilizar mejor la capacidad instalada de servicios y cortar gastos, en una perspectiva racionalizadora, integrando en la práctica cotidiana de los servicios instituciones históricamente distintas y que siempre habían trabajado separadas. Esta propuesta está en el origen de la formulación posterior del Programa de las Acciones Integradas de Salud (AIS), iniciado en 1983, y que constituye un importante antecedente de la descentralización en el sector salud al posibilitar la transferencia de recursos a los municipios y la recuperación, por un lado, de la red básica de servicios y, por outro, de la gestión colegiada, tanto en nivel federal como local, transformando ese tipo de proceso de decisión en uno de los ejes fundamentales de la política de salud, sobre todo a partir de 1985.

Con el advenimiento de la “Nueva República", 1985-1989, las condiciones políticas para la concretización de la reforma sanitaria fueron dadas cuando los reformistas, en el comando de las principales instituciones del sector, como el INAMPS, del MPAS, y la Fundación Oswaldo Cruz (FIOCRUZ), del MS, procuraron poner en práctica, aunque de forma inconexa, algunas propuestas desarrolladas dentro del ideario de disminuir la deuda social acumulada. Estos profesionales y sus equipos, apoyados por los partidos participantes de la coalisión victoriosa, dirigieron sus acciones a mantener la politización de la salud de forma a influir también en los cambios constitucionales. A partir de entonces, ganó mayor aliento la propuesta de descentralización de los servicios, y, con ella, se intensificó la demanda de una reforma tributaria y de una mayor participación de los actores y fuerzas locales en la formulación de políticas. En ese sentido, los Encuentros Nacionales de Secretarios Municipales de Salud no sól o continuaron efectuándose, sino que comenzaron inclusive a ser apoyados por el MS. Esa dinámica resulta en la creación, en 
1988, de los Consejos Estatales de Secretarios Municipales de Salud (COSEMS) y del Consejo Nacional de Secretarios Municipales de Salud (CONASEMS). Estos Consejos cumplieron en nivel local la misma función que el CONASS cumplía en nivel estatal: participar en diversos ámbitos de discusión de la política de salud.

Los salubristas-colectivistas tambien se empeñaron en revivir las Conferencias Nacionales de Salud, realizando la 8a Conferencia, en marzo de 1986, en Brasília, con masiva asistencia y participación social. Esa Conferencia fue precedida por Conferencias Municipales y Estatales que aprobarían la propuesta de reforma en asambleas de composición amplia. La propuesta de reforma fue dada a conocer principalmente a través de la revista Saúde em Debate, del CEBES, de las publicaciones de la ABRASCO y del proyecto intitulado Reunião, Análise e Difusão del nformação em Saúde(RADIS), que venía siendo desarrollado por la Escuela Nacional de Salud Pública de la FIOCRUZ desde la década de los setenta. EI RADIS había sido concebido para la captura y la difusión de informaciones referentes a la salud, y fue restructurado en el contexto de la 8a Conferencia, cuando, al lado de sus publicaciones regulares, se fundó el Jornal da Reforma Sanitária, que circuló nacionalmente desde 1985 - desde la preparación de la Conferencia -, hasta los días de la aprobación de la nueva Constitución (Brasil, 1988).

El debate realizado durante la 8a Conferencia, hasta entonces inédito en el país, legitimó la victoria del ideario político-ideológico de reforma de la política de salud. En parte porque hizo posible que, a lo largo de toda una semana, los principales periódicos del país difundieran en sus primeras planas la reunión y sus debates, mientras que las mayores cadenas de televisión exhibían entrevistas con los líderes del movimiento. Así, la propuesta de reforma de la salud se tornó de dominio público. Por otro lado, el debate en torno de la estatización versus la privatización, polarizado, estuvo en el centro de los enfrentamientos dentro y fuera de la conferencia. El sector privado se abstuvo de participar en la conferencia, en una clara estrategia de no-reconocimiento de ese foro y de las temáticas que le dieron cuerpo. Su participación se dio, de hecho, a través de la prensa, que divulgó sus críticas, protestas, opiniones y propuestas contrarias a la reformulación que estaba siendo discutida, conjuntamente con las noticias del evento, alentando a los grupos más radicales de la conferencia en sus propuestas de estatización.

La propuesta tecnico-asistencial de reforma sanitaria aprobada en la Conferencia for- malizó un concepto ampliado de salud - correlacionándola con condiciones de vida, trabajo y recreación - y institucionalizó la salud como derecho social. Proponía también la institución de un SUS, con acceso universal e igualitario, atención integral en todos los niveles, preeminencia del sector público y regulación efectiva sobre el sector privado, además de mecanismos de participación y control social. Presuponía, para su operacionalización, la revisión de los mecanismos de compra de servicios, de las relaciones con los productores de insumos y equipamientos; revisión de las fuentes y mecanismos de financiamiento (inclusive tributación); recuperación y ampliación del sistema de servicios de salud según base geográfica-territorial, además de la descentralización y del fortalecimiento del poder local.

Uno de los efectos más importantes de la 8a Conferencia, y que constituyó un nuevo agregado al edificio de la reforma, fue la creación, a través de la Seguridad Social (INAMPS), del Sistema Unificado y Descentralizado de Salud (SUDS), en 1987, concebido como una estrategia de transición para el SUS, asociado a la creación de "Consejos de Salud" como instancia de participación, de carácter deliberativo o no. También servió como termómetro, junto con la Comisión Nacional de la Reforma Sanitária (CNRS), de composición amplia en la cual la corriente reformista fue derrotada, para medir la fuerza de los conflictos y el tamaño de las resistencias, provenientes tanto del sector privado como, muchas veces, de los propios aliados en la lucha democrática y que convergieron inevitablemente en la Asamblea Nacional Constituyente (1987-1988). Conscientes de la oposición, y con el propósito de garantizar la adhesión de los Constituyentes, los sanitaristas-colectivistas organizaron la Plenaria de las Entidades de la Salud en la Constituyente que actuó como fuerza de presión en el Congreso. Montada como "una articulación suprapartidaria”, la Plenaria congregó cerca de dos centenas de entidades y consiguió construir "un pacto progresista" - la Enmienda Popular - que sobrepasó coyunturalmente las divergencias existentes en el movimiento sanitario (Teixeira, 1987, 1989). Esa Plenaria fue decisiva para la aprobación de los principios de la reforma y enfrentó, una vez más, una fuerte oposición del sector privado sectorial, pesadamente representado y actuante en el Congreso. La tesis "salud como derecho de ciudadanía y deber del Estado", lema de la bandera de lucha sectorial, fue inscrita en la nueva Constitución, en 1988. Las CNSs fueron institucional izadas como foros democráticos de debate de la política sec- 
torial, a ser realizadas cada cuatro años, lo que viene ocurriendo con regularidad.

La nueva Constitución brasileña aprobó un Welfare State en los moldes europeos. Los beneficios se tornaron universales, independiente del vínculo contributivo del ciudadano. Se unificaron y ampliaron las fuentes de recursos federales, y se creó el Presupuesto de la Seguridad Social (OSS), dirigido al financiamiento de la salud, seguridad y asistencia social. Además, se inscribió el derecho de acceso universal a cualquier servicio de salud financiado por los cofres públicos. De hecho, era un avance en lo referente a la noción del derecho social universal. Entretanto, como observó Fiori (1991), poco se discutió en el Congreso Constituyente sobre la forma de financiamiento relacionada a la incorporación de estos nuevos derechos y, al mismo tiempo, se aprobaron medidas redistributivas sin garantizar los recursos necesarios para su implementación. El proceso de negociación que precedió a las etapas finales de la Constituyente y los acuerdos efectuados acabaron por introducir innumerables inconsistencias y ambigüedades en la nueva Constitución, que fueron remitidas a las subsecuentes etapas de reglamentación jurídica. El debate siguió en el campo legislativo, tanto en nivel federal, donde se dio la reglamentación de las Leyes Orgánicas de la Salud, aprobadas en 1990, como en nivel estatal y municipal, con la promulgación de las constituciones estatales y las Leyes Orgánicas de Municipalidades.

Paralelamente, y de manera independiente de la discusión de la Constituyente, se verificó un movimiento real de privatización del sistema de asistencia y financiamiento sectorial, como corolario de la crisis financiera de los años ochenta (Faveret \& Oliveira, 1989; Médici, 1990; Viana et al., 1990). Si bien los gobiernos de la "Nueva República” no lo promovieron directamente, contribuyeron con su pasividad al crecimiento del mercado privado de servicios de salud, totalmente desregulado, como una alternativa a la crisis y a su propia bancarrota. Esa dinámica no fue identificada oportunamente por los sanitaristas-colectivistas, quizá porque menospreciaron su importancia para reorganización del sistema de salud.

Siendo así, en el proceso de hacer efectivo Ios ideales Constitucionales, se entrelazaron dinámicas contradictorias que repercutieron en el sector salud de forma particular. Mientras que las medidas de aplicación de la reforma privilegiaban la descentralización y pregonaban el fortalecimiento del sector público, el OSS no fue respetado. Los recursos para la salud disminuyeron de manera importante en el período imediato de su implementación, pari passu a la homogeneización del consenso político neoliberal durante el gobierno Collor de Mello (1990-1992), recuperándose parcialmente de forma muy inestable en los dos períodos de Fernando Henrique Cardoso (iniciados en 1994), cuando el país pasó a aceptar claramente los condicionantes definidos por la comunidad financiera internacional y la actuación del Estado y los instrumentos de política sectorial han sido subordinados al objetivo primordial de mantener el equilibrio macroeconómico. De tal forma, a partir de ese momento, la lógica de la racionalidad económica pasó a nortear la reforma, lo que ha provocado fuertes tensiones entre el ejecutivo y los adeptos de la "reforma sanitaria ciudadana", muchos de ellos pertenecientes al "Movimiento de reforma sanitaria", pero entonces diputados y senadores, o asesores en el Congreso y secretarios de salud estatales y municipales de los principales partidos de oposición. La adopción de propuestas de reforma administrativa del Estado, volcadas hacia el quiebre del " monopolio" del Estado en el sector completó el cuadro de contradicciones del proceso de reforma sectorial.

El proceso de descentralización avanzó y es el eje central de la construción del SUS, pero manteniendo fuerte presencia del nivel federal. El proceso de decisión se hizo más complejo con la creación, en 1990, de los Consejos de Salud - nacional, estatales y municipales - colegiados de decisión y control social; y las Comisiones Intergestores - la federal (Comisión Intergestores Tripartite - CIT), creada en 1991, y las estatales (Comisiones Intergestores Bipartites - ClBs), en 1993 - órganos técnicos de negociación compuestos por representantes de los secretarios de salud y de la tecnoburocracia del MS, en el caso de la CIT, y por los representantes de los secretarios municipales de salud y de la secretaría estatal de salud, en él de las CIBs. Estos órganos se transformaron en instancias de decisión, pero paulatinamente las Comisiones Intergestores pasaron a dominar el proceso, sobre todo la CIT, donde los representantes de los secretarios de salud de los estados y municipios juegan un papel importante (Almeida et al., 1999). Las conferencias y los consejos de salud - estatales y municipales - actuan con regularidad, pero su dinámica reflite el juego de fuerzas del poder local, evidenciando el dilema de construcción de un sistema único de salud en un país continental, con enorme diversidad y heterogeneidad en todos Ios niveles. En paralelo y en respuesta al acumulo de demandas civiles en contra del sector de seguros privados, en los últimos años, el go- 
bierno y el Congreso entraron en un arduo proceso de regulación de ese sector, que cuenta con cabildeos poderosos, bien organizados y fuertemente arraigados en la política sectorial.

EI SUS municipalizado tropieza en las profundas disparidades regionales, en los cuellos de botella colocados por la situación económica y en la falta de coordinación y de mecanismos redistributivos más efectivos. Algunas inovaciones, como la creación de agencias reguladoras autónomas (como la de vigilancia sanitaria, la de regulación del sector de seguros privados), la propuesta del ejecutivo federal de privilegiar la atención básica en el ámbito municipal a través del pago per capita, de fomentar con incentivos programas especiales como el de Salud de la Familia y el de los Agentes Comunitarios, sin una adecuada restructuración de la red de servicios, traen el riesgo de aumentar o profundizar la fragmentación del sistema y promover la focalización en determinados tipos de atención para grupos específicos. A su vez, los municipalistas beneficiados con nuevas cuotas de poder acabaron por incorporar algunas de las "inovaciones" gerenciales que resultaron tanto de sus experiencias en la administración del sector, como de la difusión masiva de los "nuevos modelos de reforma" (tercerización, introdución de mecanismos competitivos, gerencialismo) (Almeida, 1995, 1996, 1999, 2001) a cargo, sobre todo, de los organismos internacionales. EI SUS está inmerzo en la etapa de contrarrestar procesos de naturaleza macro, que fijan nuevas pautas para viejos atolladeros del sector, como es la incorporación de inovaciones, la regulación y la cuestión financiera. Por otro lado, recien fue aprovado un porcentaje definitivo de recursos del OSS para la salud, importante punto en la agenda universalista de reforma desde la Constituyente.

Por lo tanto, es en el interior de las dinámicas racionalizadora y universal ista, instrumentalizadas por las diversas fuerzas sociales y políticas en disputa por el control de modelo de desarrollo, que se va desarrollando el proceso de reforma sectorial. Evidentemente, un nuevo sistema de salud viene siendo gestado, cuya mayor característica es constituirse en un sistema abierto a los diversos grupos sociales y que logró cambiar su eje de decisión, exclusivamente centrado en Brasília para la incorporación de actores de los estados y municipios, aunque la implementación de la reforma no garantice todavía el logro de mejores niveles de equidad, particularmente en una coyuntura de larga duración que continúa generando pobreza y a la cual no se le ve fin en un futuro cercano.
La nueva salud pública en México:

los especialistas en lucha por el control de la salud pública

El proceso de reforma de la salud en México tiene sus antecedentes en los años setenta cuando se empieza a discutir, entre otros temas, la relación entre los resultados de la industrialización y la complejidad del cuadro epidemiológico caracterizado por la superposición de las enfermedades de la pobreza con las del desarrollo (López-Acuña, 1980). Es en 1983 que arranca un proceso de reconfiguración de la base institucional del sector salud que todavía está en curso. Esa reconfiguración hacia un nuevo modelo institucional-organizacional fue concomitante a la aceptación, por el gobierno mexicano, de la agenda de ajuste estructural capitaneada por los organismos financieros internacionales que, entre otras cosas, pretendía disminuir el papel del Estado en la condución del desarrollo económico y social.

La reforma en cuestión está siendo llevada a cabo en una situación político-institucional y socio-sanitaria que se consolidó y expandió bajo la hegemonía ideológica de un Estado intervencionista. Por un lado, la Secretaría de Salubridad y Asistencia (SSA), que actúa sobre las condiciones de salud de la población en general y promueve políticas médico-sanitarias. Por otro, las instituciones de Seguridad Social específicamente diseñadas para algunas categorías profesionales, dirigi das a restaurar la salud individual de los trabajadores vinculados a los sectores más dinámicos de la economía y a responder a las demandas de las organizaciones corporativas del sector obrero y de servicios. Ese complejo institucional operó sobre el proceso salud-enfermedad a partir de una visión clínica, creando un mercado de trabajo cautivo para los médicos en las instituciones de salud, y contó, además, con un grupo de profesionales formados para atender la dimensión colectiva de la enfermedad en la Escuela Nacional de Salud Pública, fundada en 1922, como un organismo de la Secretaría de Salud y, posteriormente, en los propios cursos de la SSA.

Ese complejo institucional fue considerado exitoso hasta la mitad de la década de los setenta, tanto por los médicos como por la industria privada, y por las propias fuerzas políticas articuladas en torno del hegemónico PRI y, en particular, los sectores obrero y empresarial. Las voces disonantes que, hasta ese momento, se habían hecho escuchar pertenecían a los médicos residentes que habían participado de la huelga de 1964, secundadas por las de algunos pequeños grupos sindicales disidentes de 
la ciudad de México, presentes tanto entre los trabajadores de la SSA como del Instituto Mexicano del Seguro Social (IMSS - 1942), donde había ex-activistas del 1964 y del movimiento estudiantil de 1968. También se oponía al status quo un grupo académico, minoritario en la Facultad de Medicina de la Universidad Nacional Autónoma de México (UNAM), y posteriormente consolidado en la Universidad Autónoma Metropolitana - Xochimilco, a partir de su fundación en 1970, en el departamento de Medicina Social. Dicho grupo, algunos de cuyos miembros estaban vinculados a sectores de izquierda, se articulaba en torno a la discusión de la Salud Colectiva formulada en Brasil, de los determinantes de clase sobre el proceso de salud-enfermedad, y de la crítica del modelo médico-curativo presente en las instituciones oficiales de Seguridad Social.

El deliniamento de conflictos políticos en el interior de la estructura de poder sectorial fue en parte encauzado por los resultados contradictorios del crecimiento económico y produjo divisiones dentro del sanitarismo comprometido con el régimen. Dichos conflictos alimentaron, en el seno de algunos grupos vinculados al PRI, la necesidad de renovar las élites técnico-políticas del campo de la salud identificadas con las prácticas clientelares-corporativas, sustituyéndolas por otras más sensibles a un cuadro de demandas propio de una sociedad compleja donde configura, al lado de los reclamos de servicios públicos de salud, una naciente clase média urbana que presiona la expansión de la atención médica curativa. En ese proceso, se destacó un grupo de médicos oriundos de la UNAM que reclamaba la necesidad de introducir elementos de planificación y mejorar la formación de recursos humanos para modernizar el desempeño de las instituciones públicas. En el centro de sus preocupaciones estaban los altos costos de la atención médica, la mala distribución de los recursos médico-sanitarios, los limitados resultados de las intervenciones sobre las enfermedades de la pobreza, y la presión de los médicos recién formados sobre el mercado de trabajo. Como resultado de estas preocupaciones y de los vínculos políticos de ese grupo con el Estado, fue designado para la Secretaría de Salubridad y Asistencia, en el gobierno de Miguel de la Madrid (1982-1988), un bioquímico proveniente de la investigación básica, ex-rector de la UNAM, y conocido como "mano de hierro" por los sindicatos y estudiantes universitarios, el doctor Guillermo Soberón. Su designación representó una ruptura con la tradición prevaleciente en el sector, que mandaba nombrar para ese tipo de cargos a expertos en salud pública, o bien a funcionarios con trayectoria en la gestión estatal de los servicios de salud (Mercer, 1984).

El resultado fue la puesta en práctica de la propuesta conocida como “Reforma Estructural" (Soberón, 1983). Dicha propuesta buscaba mejorar el acceso a los servicios de salud y racionalizar recursos a través de la integración de las instituciones de Seguridad Social con las de la SSA, bajo la coordinación de esta última, constituyendo un Sistema Nacional de Salud descentralizado, ágil, y que contara con la participación de los diferentes niveles de gobierno y de prestadores de servicios de salud públicos, privados y sociales. La puesta en práctica de ese proyecto, para el cual fueron necesarias nueva base jurídica y modificaciones en la Secretaría de Salud basadas en una concepción centralizadora del poder en las manos del Secretario, representó una amenaza a los intereses de determinados segmentos sociales y de poder del sector salud. Tanto la burocracia del IMSS - aliada al sindicalismo oficial - como también gobiernadores y sindicatos en contra de la descentralización y segmentos de la burocracia de salubridad contrarios a los rumbros que estaba tomando la política de salud movilizaron sus recursos políticos para obstaculizar la acción del Secretario de Salud. Por si fuera poco, los cambios fueron ejecutados por un nuevo grupo técnico-profesionista y político, compuesto de juristas, administradores y médicos oriundos de la UNAM, muchos de los cuales acompañaban a Soberón desde los años de su ejercicio como rector. La entrada de esos profesionistas provocó el desplazamiento de médicos y enfermeras salubristas tradicionales y fue mal vista porque ellos venían de áreas ajenas al sector salud o habían sido formados en el exterior, sin vivencia, sensibilidad y conocimientos suficientes para actuar junto a la población carente de México (Loewe, 1988).

Además, estos cambios se daban en una coyuntura de desempleo y de disminución del poder adquisitivo del sector obrero, en la cual las negociaciones político-económicas para buscar una salida a la crisis necesitaban contar con el aval de los trabajadores y de los políticos del PRI (Tello, 1989). A eso se sumaba la poca legitimidad de la Secretaría de Salud, tanto junto a los grupos asistidos como junto a los trabajadores de la seguridad social, debido, en parte, a las diferencias presupuestales, de servicios, de instalaciones, de equipos y de salarios. Como si no fueran pocos los problemas para el proyecto de reforma, el sector salud tuvo que enfrentar brotes de enfermedades ante- 
riormente controladas, como el sarampión, y un nuevo recorte de presupuesto en 1985, además del sismo de ese mismo año, que destruyó gran parte de las instalaciones médicas de la ciudad de México.

Aun el proyecto de "Reforma Estructural" terminó por ser bloqueado temporariamente, asentó las bases jurídicas de los cambios futuros y comenzó a debilitar la estructura de poder anterior. Al igual que en otras dependencias federales de finales del período del presidente De la Madrid, la situación en las instituciones de salud había cambiado. No sólo los recursos fueron reducidos y con ellos la capacidad para generar servicios y empleos, como también fueron afectados el prestigio y el alcance del poder de la tecno-burocracia, la cual, al igual que el corporativismo y sus aliados políticos, estaba siendo sometida a una fuerte crítica por parte de grupos de la sociedad civil, en particular del sector empresarial. Como parte de esos cambios, nuevos técnicos, con un discurso racionalizador y, en cierta medida, de espaldas a la retórica revolucionaria, ocuparon posiciones importantes en las instituciones de salud. En la Secretaría del ramo, por ejemplo, fue creado, en 1984, el Centro de Investigación en Salud Pública (CISP), para asesorar al secretario en la toma de decisiones a través de la “producción de información no sesgada y libre de presión política” (Secretaria de Salud, 1987:19).

El Centro albergó jóvenes médicos exalumnos de la UNAM que, bajo el liderazgo del doctor Julio Frenk, empezaron a formular un nuevo concepto para la salud pública, lo que fue llamado la Nueva Salud Pública. Se trataba de una novel especialización del campo médico referida a la "salud de las poblaciones", cuyo objetivo era dar a conocer las necesidades de la población, y solucionar la demanda de forma a establecer un equilibrio entre esas necesidades y los recursos, definidos por ellos mismos como escasos. En ese sentido, la Nueva Salud Pública debería producir información, nuevos indicadores y prácticas de gerencia dirigidos a fortalecer la capacidad de gestión de los sistemas de salud y orientar la toma de decisiones, interponiendo esas informaciones entre el médico y su práctica y entre el servicio y la sociedad (Frenk, 1994).

De ahí el adjetivo “nueva”: según uno de sus idealizadores, el término fue introducido para definir el objeto que se procuraba comprender y sobre el cual se quería intervenir - la dimensión en población de la enfermedad - por oposición a la medicina, que cuida del individuo, y de la biomedicina, que investiga a nivel intra- celular, y así incluir la salud pública en el campo de las ciencias de la salud. También se buscaba diferenciar la definición tradicional de salud pública que hasta entonces alimentaba la práctica de las instituciones de salud del Estado, en las cuales lo público se refería al ámbito del Estado, y también de otras definiciones en uso, como, por ejemplo, la de la Salud Colectiva que se discutía en Brasil y en la maestría de Medicina Social de la UAM - Xochimilco, focalizada en el social. Al definir la salud pública como una ciencia en oposición a su práctica pública, demarcaba un campo de trabajo y una frontera con relación al rol que ocupaba como ámbito del Estado: deja de ser una instancia que responde por los problemas sociales de las enfermedades para tomar el lugar de inteligencia del modelo técnico-asistencial. El papel de la salud pública - definida como ciencia - pasa a ser el de garantizar el aceso a los recursos técnico-científicos generados por las investigaciones biomédicas y médicas, apoyado en una firme base de investigación que hiciera posible conocer con precisión las necesidades en salud y su distribución en la población, así como las modalidades idóneas de organización de la atención.

La nueva corriente técnico-científica, que de ahora en adelante llamaremos de neosalubrista, asumió una dimensión más institucionalizada cuando el doctor Soberón creó el Instituto Nacional de Salud Pública, en 1987, desplazando la antigua Escuela Nacional de Salud Pública de las tareas de formación de recursos humanos, producción y reproducción del conocimiento. El nuevo instituto tendría la misión de ser la vanguardia de la reforma del sector salud, y conferir rango académico a la Nueva Salud Pública, al tiempo en que diseñaría las alternativas de políticas sectoriales y formaría recursos humanos para la salud. Soberón también garantizó la influencia de la nueva corriente al exterior del ámbito técnico-científico. Convocó a un grupo selecto de empresarios a crear la FUNSALUD para "atenuar posibles faltas de continuidad consecuentes a la cronología sexenal" (FUNSALUD, 1987:10), o sea debido a los cambios de presidente de seis en seis años. De acuerdo con Soberón, la creación de FUN SALUD era parte del esfuerzo del gobierno por promover la participación comunitaria que, en sus palabras, podía "nutrirse del trabajo conjunto, sea de un centenar de prominentes empresarios, sea de un comité de salud integrado por un puñado de campesinos en una pequeña aldea" (FUNSALUD, 1987:11). En ese contexto, como una expresión sectorial de la participación organizada de los empresarios, FUNSA- 
LUD tenía como propósito garantizar el enlace y la comunicación entre los dirigentes del sector privado y los funcionarios gubernamentales para el conocimiento de la situación de salud, de los programas vigentes y de la perspectiva bajo la cual operaba la autoridad sanitaria. En documentos posteriores de FUNSALUD, su creación pasa a ser presentada como una iniciativa de un grupo de empresarios y no más como del doctor Soberón (FUNSALUD, 1993).

La Fundación surgió así como una institución no-corporativa, con una exclusiva membresía compuesta por cuadros del sector médico, miembros destacados del PRI y del sector empresarial, algunos de los cuales con intereses económicos directos en el sector salud en particular, en el mercado de vidrio, en materiales plásticos y otros insumos de la industria químico-farmacéutica. Algunos de estos empresarios eran próximos al gobierno y a su partido y otros más cercanos al Partido Acción Nacional (PAN). Para su desarrollo institucional, FUNSALUD contó también desde el inicio con el apoyo financiero de grandes fundaciones privadas de Estados Unidos, centros de poder económico y político, entre ellas, la Corporación Carnegie de Nueva York. Su patrimonio inicial fue constituido por las aportaciones de los socios y por donativos en igual monto del gobierno federal, durante la gestión del doctor Soberón como secretario de Salud.

Así, al darse el "destape" de Carlos Salinas de Gortari como candidato del PRI para el nuevo período de gobierno, los neosalubristas estaban en condiciones de continuar a influir en la pugna por el control de las orientaciones de desarrollo del modelo médico de atención. Para los neosalubristas, el candidato anunciado representaba la continuidad de la política de apertura económica puesta en práctica por De la Madrid, aunque apostaban en un nuevo reacomodo de los grupos de poder capaz de dar sustento político a los cambios iniciados en el ámbito de la reforma del sector salud, así como en la institucionalización de nuevas formas de relación entre el Estado y la sociedad. En esos momentos, los neosalubristas consideraban que los cambios económicos y políticos eran irreversibles y que el reto consistía en hacer uso oportuno de los momentos de crisis para cimentar bases de poder que permitieran controlar el proceso de cambio que la reforma requería. Para eso, FUNSALUD, que había sido pensada tan sólo como un canal de influencia del sector privado junto a las políticas de salud, logró transformarse en un actor social que demandaba un espacio de participación en la toma de decisiones, y que postulaba con firmeza un cambio de orientación en el modelo de organización de los servicios de salud, de un orientado por la lógica del público a otro, bajo la lógica del privado. En esa lucha, los neosalubristas desempeñaron un rol importante de constructores y operadores del enclave técnico-científico de la reforma, como será discutido enseguida.

Los neosalubristas y su obrar por el cambio de dirección en el modelo de atención médico

Después de la controvertida victoria del candidato del PRI, Carlos Salinas de Gortari, para el período de 1988-1994, el país pasó por momentos político-ideológicos importantes, marcados por la rearticulación de fuerzas políticas, económicas y sociales como parte de un proyecto mayor de reforma del propio Estado mexicano, en lo cual el presidente entrante hizo uso de la política social para organizar nuevas base de apoyo (Warman, 1994). En el encaje de las piezas que preparaba el ejercicio del poder por parte de Salinas de Gortari, el titular de la Secretaría de Salud designado resultó ser ajeno al cuadro de los jóvenes investigadores nutridos de los valores y conocimientos de la Nueva Salud Pública, contrariando la expectativa de Soberón. El nuevo titular era el médico-militar Jesús Kumate, aun un próximo ex-colaborador de Soberón en la secretaría, miembro de la Academia de Medicina y del Colegio Nacional, e investigador con tradición, no dió seguimiento a la política de su antecesor, pautada por el enfrentamiento con los grupos tradicionales del sector salud. Por otro lado, la principal agencia de elaboración de políticas sociales del período de Salinas pasó a ser el recién creado Programa Nacional de Solidaridad (PRONASOL), elaborado bajo la coordinación de un grupo de destacados intelectuales de izquierda de lo cual los neosalubristas no formaban parte. La reforma del sector salud en su dimensión institucional-organizacional fue postergada, mientras se buscaba renegociar los compromisos institucionalizados con el sector obrero y promover una nueva sociabilidad, políticamente orientada por los postulados y programas de PRONASOL (Warman, 1994).

En ese contexto, en su propósito por obrar a favor de la reforma del sector salud, los neosalubristas se empeñaron en transformar el nuevo INSP en una institución de enclave técnico-científica de la reforma, al mismo tiempo que buscaban hacer de FUNSALUD un think tank de los intereses del sector privado para 
con la salud. La nueva orientación científica de la salud pública practicada por los neosalubristas fue respaldada tanto por el selecto grupo de médicos de la Academia Nacional de Medicina, y en la cual algunos de los jóvenes neosalubristas pasaron a integrar, como también por el principal órgano de apoyo a la investigación científica, el Consejo Nacional de Ciencia y Tecnología (CONACYT). Cuanto a la Fundación, sobre todo después de 1992, debía afirmarse como organización civil, expresión del desarrollo social mexicano, no perteneciente ni al Estado y ni al sistema político, propositiva e independiente, afianzada en su capacidad de gestión y de organización. Esto es, tenía que presentarse de manera convincente como un medio especialmente adecuado para promover la noción de lo privado como agente de solidaridad capaz de ocupar el lugar del Estado. Para eso fue decisiva la profesionalización en la condución de la propia organización y de la conformación de un staff capaz de contribuir para formular problemas, sugerir lo que hacer y crear un mapa propio de intereses en torno a la reforma, de lo que se ocuparía la propia Fundación.

En efecto, FUNSALUD dirigió parte de sus energías a actividades filantrópicas y acciones altruistas de forma a demostrar la preocupación del sector privado con la salud de la población, y para probar que una nueva lógica actuaba en la manera de abordar esos problemas, que articulaba la salud del individuo con la de más salud por el dinero que se invierte (Soberón, 1983). En la visión del doctor Soberón, el sistema de salud mexicano estaba pasando por otro momento sin haber terminado todavía el "cambio estructural". Ahora, la salud es un elemento fundamental de la economía de los países y "en la actualidad se gasta mucho dinero en salud y hay preocupación porque los costos siguen creciendo y, además, ahora ya no está obteni endo dividendos por el dinero que se gasta. Hace falta más dinero para la salud, pero también hace falta más salud por el dinero quese invierte y ésta es una gran preocupación..." (G. Soberón, 1995, comunicación personal).

Dichas actividades, realizadas por FUNSALUD con recursos aportados principalmente por el sector privado, contemplaban desde acciones de intervención directa hasta apoyos financieros para la formación de cuadros y para la promoción de investigación científica. Al actuar en el ámbito asistencialista, los neosalubristas estaban de acorde con la nueva orientación de la política social del gobierno mexicano que, cada vez más, incentivaba la participación de otros sectores sociales en la prestación de servicios asistenciales, y, al mismo tiempo, se afinaba con la cultura política de las grandes fundaciones privadas de Estados Unidos, sus asociadas.

FUNSALUD se empeñó también en erigirse en importante vehículo de divulgación y defensa de la reforma, y en el promotor de una nueva agenda de investigación, afinada con los parámetros de las agencias internacionales de desarrollo, en particular del Banco Mundial. Eso se tornó posible con la creación, en 1993, de una nueva sección de FUNSALUD, Ilamada "Economía y Salud", concebida como un "centro de estudios y de opinión del sector privado" (FUNSALUD, 1995). El nuevo organismo fue puesto bajo la dirección del doctor Julio Frenk, recién llegado de estancias de formación e investigación en la Universidad de Harvard (Estados Unidos), donde había convivido con los autores del I nforme sobre el desarrollo mundial 1993 (FUNSALUD, 1994).

Con la creación del Centro, FUNSALUD comenzó a manifestar, en diferentes publicaciones, su intención de ocupar, a través del nuevo organismo, tanto en el plan nacional como en otros países del Tercer Mundo, el lugar de “inteligencia institucional" de sistemas de salud capaces de responder a las necesidades específicas de cada situación y de apoyar a los respectivos gobiernos en sus intentos de reforma sectorial. Como parte de ese esfuerzo, “Economía y Salud" apoyó el discurso de la crisis del modelo estatal de atención a la salud, a través de la elaboración de diagnósticos y de la realización de encuestas, que fueron consideradas como expresión de la voz activa de los ciudadanos, con el propósito de abogar por la extracción de los elementos nocivos de los sistemas de salud. Esa producción fue plasmada en diferentes publicaciones de la propia FUNSALUD, en particular en los libros Economía y SaIud (1994) y Observatorio dela Salud (1997). La Fundación también recebió a partir de 1997 apoyo financiero para fomentar, financiar y divulgar investigaciones sobre las reformas sectoriales en todo el mundo, creando el programa International Clearinghouse for Health Sector Reform Initiative (ICHSRI), financiado con un pool de recursos oriundos del Banco Mundial, de la Fundación Rockefeller y de la OMS, que actuó hasta el año 2000. Como parte del proyecto ideológico de difusión de determinada concepción de reforma sectorial articulada a una propuesta de divulgación de resultados de investigación para apoyar el policy making sectorial, fue creado el Núcleo de Acopio, Análisis y Difusión de Información sobre Iniciativas de Reforma (NAADIR), vinculado al ICHSRI, 
que, en un primer momento, publicó el boletín internacional Informing and Reforming, de ámbito mundial, y, posteriormente, desde 1999, el Informando y Reformando/AL, para la región de América Latina, con el apoyo del Banco Interamericano de Desarrollo (BID) y de la OPS, además del INSP y de la própria FUNSALUD. EI NAADIR creó también una base de datos electrónica para difundir las narrativas de reforma, sea en nivel mundial o regional.

Al mismo tiempo, FUNSALUD establecía una relación próxima y multifacética con el gobierno federal, que le permitió limitar ámbitos de dependencia mutua, mientras que, en otras esferas, resguardó su autonomía. FUNSALUD fue invitada a participar en diferentes comisiones oficiales creadas en el contexto de la firma del Tratado de Libre Comercio de América del Norte - TLCAN (el NAFTA - North America Free Trade Agreement), apoyó la creación de normas de regulación del mercado de servicios de salud y, como desdobramiento, promovió la formación de la Sociedad Mexicana de Calidad de Atención a la Salud, en 1992. Poco a poco, FUNSALUD fue transformándose en un balón de oxígeno para el ejecutivo: por un lado, proporcionando cuadros de su cuerpo técnicocientífico para los equipos de gobierno; y, por otro, como resultado de sus vínculos con sectores del PRI y con el sector empresarial interesados en continuar promoviendo cambios en las políticas de salud, participando en la campaña presidencial del candidato del PRI, Ernesto Zedillo (1994-2000), como parte integrante de la Comisión de Elaboración de los Programas de Gobierno. También fue haciéndose más presente en el centro de decisiones del sector, logrando extender sus influencias hasta las instituciones de seguridad social. Esa influencia materializó en la formación de una organización "extra muros", fuera de las presiones de los grupos burocráticos internos a la Seguridad Social, el Centro de Desarrollo Estratégico para la Seguridad Social (creado en 1994), con la función de asesorar al gestor de la Seguridad Social. Ese Centro, junto con FUNSALUD, tuvo un papel relevante en la ingeniería de la reforma de la Ley del IMSS (1995) que, entre otros cambios, permitió el uso privado delos recursos de la seguridad social.

Aunque, más una vez, no lograron indicar el Secretario de Salud, esos especialistas influyeron en la propuesta que orientó el Programa de Reforma para el Sector Salud (Poder Ejecutivo Federal, 1996) del presidente entrante, presentado en 1996, que proponía "el abandono de la estrategia [previa] dela seguridad social y su sustitución por una política que combinaba prioridad al mercado privado deservicios desaIud y mecanismos de alivio de la pobreza" (Laurell, 2001:299). Además, el sistema de salud sería descentralizado, sería implementado un paquete básico de servicios esenciales y un sistema de mecanismos de co-pagos según comprobación de renta; posteriormente, los servicios públicos (clínicas y hospitales) serían transformados en entidades autónomas (Laurell, 2001). El modelo teórico de reorganización de sistemas de salud Ilamado "Pluralismo Estructurado" constituyó el punto de apoyo para la formulación de ese programa de reforma, y su elaboración fue resultado de un trabajo colectivo de especialistas, en colaboración con el Banco Mundial, del cual participó el Dr. Julio Frenk. Ese modelo está basado en la separación de funciones de financiamiento y prestación de servicios y definición de un específico rol de regulación para el Estado, y había sido puesto en práctica en la reforma de la seguridad social en Colombia, en 1993. En él el sector privado presta servicios, la contribución social financia y el Estado regula, para ofrecer opciones plurales al usuario bajo los principios de la libre capacidad de elección del prestador de servicios por el consumidor y la garantía de la equidad. La equidad sería conseguida por la combinación de algunos mecanismos: financiamento público, que para los pobres toma la forma de subsídios y para los otros grupos sociales contribución obligatoria (valor de cuotas diferenciadas pagadas de acuerdo con la capacidad de pago de cada uno); implantación de distintos regímenes de afiliación al sistema (contributivo, subsidiado y vinculado); y diferentes paquetes básicos de atención para cada uno de ellos. Esos paquetes son definidos con base en criterios de costo-efectividad, según el principio de la selectividad frente a recursos escasos. La participación del Dr. Julio Frenk en la elaboración teórica de ese modelo marcó también el inicio de otra vocación de FUNSALUD, la de influir en la agenda de reforma sectorial en la región latinoamericana. Entretanto, diferente de Colombia, la reforma sectorial en México no se implementó como un cambio abrupto y radical.

Esas iniciativas reflejaban la institucionalización de una visión específica de reforma para el sector salud, y de un marco analítico en el cual la reforma fue basada en "un concepto de eficiencia dela acción pública queúnicamente la midesegún criterios de racionalidad económica, definida como universal e intemporal" (Marques-Pereira, 1994:228). Reflejaban también una estrategia de poder que apuntaba hacia espacios que superaban las fronteras nacionales. La reforma era considerada como un fe- 
nómeno global independiente de la práctica concreta de cada país. En ese proceso, FUNSALUD ocupó también el lugar de catalizador nacional e internacional - de los intereses en torno de la reforma del sectorial. En ese papel, FUNSALUD asumió la misión de convertirse en la formuladora de la base técnico-científica de la reforma y de situarse en el lugar, a un tiempo, de proveedora y de promovida, a partir del cual podía, por un lado, tejer la conexión entre organismos internacionales, empresas privadas, instancias de gobiernos y comunidad técnico-científica, canalizando relaciones que resultaban facilitadas por sus contactos estratégicos con las élites dirigentes, accesos a la información, recursos humanos y de otra naturaleza. Por el otro lado, FUNSALUD fue promovida al nivel de grupo de expertos capazes de asesorar a los tomadores de decisiones en el país y fuera de él. Esta función los hizo actores en el tránsito de una sociedad en búsqueda de una nueva dirección para su desarrollo, cuyo sentido y naturaleza tendrían que ser indagados y estudiados, además de reafirmar sus aspi raciones de poder más allá del ámbito nacional.

Es evidente que la creación, consolidación y expansión de FUNSALUD son indicativos de modificaciones importantes en las relaciones de poder del sector y en las formas de relacionamiento entre el Estado, la sociedad y el mercado en el sector salud, aunque no sea posible afirmar, por lo menos por ahora, que dicho proceso se haya inscrito en una trayectoria de democratización y de resultados positivos con relación al proceso salud-enfermedad-atención, en particular para los grupos excluídos del mercado.

A su vez, la victoria del presidente Vicente Fox (en 2001), candidato del PAN, conocido por sus posiciones de centro-derecha, cierra un ciclo de 70 años del PRI en el poder, y la indicación, con el apoyo del sector privado, del Dr. Julio Frenk como Secretario de Salud, sacrificando incluso candidatos panistas, consolida una tendencia inaugurada en 1982 en el ámbito del ejecutivo nacional, de pérdida de fuerza de la visión de la salud como un derecho social garantizado por el Estado a una basada en el poder de compra del "consumidor". Es en ese marco que surge la propuesta, anunciada en junio de 2001 por el secretario, de crear un "Seguro Popular para la Salud", formulada por FUNSALUD y apoyada por las Instituciones de Servicios Especializados en Salud (ISES) - creadas en 1999, en los últimos días del zedillismo - con la finalidad de normar el mercado de seguros médicos privados. El Seguro Popular para la Salud sería una estrategia que permitiría canalizar para el sector privado a través de las aseguradoras, los Ilamados "gastos de bolsillo" de muchos millones de mexicanos pobres que no tienen acceso a la seguridad social y que no logran ser atendidos en los servicios públicos. El impacto esperado de esa medida sería más sobre la organización del mercado de servicios privados y el acceso a determinados servicios de salud que sobre la equidad y la promoción de la salud, problemas estructurales del sistema de salud en proceso de reforma.

Sin embargo, el curso de esas decisiones será determinado por el juego de las alianzas entre el actual secretario del ramo y el sector privado, como también por el proyecto de legitimidad del PAN y por la presión de otras fuerzas políticas presentes en la sociedad. Entre éstas, destácase en particular la del PRD, que actualmente gobierna la Ciudad de México y otros estados y que ha defendido el fortalecimiento de la dimensión pública de la salud, como también algunas otras tendencias presentes en el sector sindical y en el PRI. Por otra parte, será determinado también por las condiciones concretas de enfermar y morir de millones de mexicanos que apostaron en el cambio político y en una nueva generación de políticas de salud animada por ciudadanos y no por puros "consumidores".

\section{Conclusión}

Este estudio muestra que, tanto en Brasil como en México, los especialistas en salud pública actuaron como actores cuyo papel fue y continúa siendo el de brindar la base técnico-científica a partir de la cual se justificó una específica distribución de los bienes y recursos proporcionados por el sector salud y no otra. Los investigadores involucrados, tanto los pertenecientes a la salud colectiva en Brasil como a la nueva salud pública en México, además de producir y divulgar un volumen significativo de trabajos técnico-científicos, aportaron nuevas ideas en torno al proceso salud-enfermedad-atención y pasaron a formar operadores de los sistemas de salud. También en ambos casos, movidos por motivos distintos, esos investigadores y profesionales de la salud opusieran a la salud pública dominante en las instituciones de sus países, lograron construir propuestas de reforma de los sistemas de salud de sus países que servieron de plataforma para determinadas fuerzas político-sociales, además de participar en el debate internacional en torno a los ámbitos de acción del Estado en el proceso de salud-enfermedad-atención, que se 
expresó en propuestas de reorganización de los sistemas de servicios de salud.

Sin embargo, aun los dos grupos reaccionaron en contra del establecido, se sitúan en polos opuestos del espectro político-ideológico, lo que implicó naturalmente diferentes concepciones de salud pública, de reforma y de ciudadanía, como también de alianzas para llevar a cabo sus proyectos. En el caso de Brasil, desde los años 70, los investigadores y profesionales aglutinaron luchando en contra del poder militar y de su política de salud y formuIaron el concepto de Salud Colectiva, en la perspectiva de recuperar el lugar de lo social dentro del campo de la salud como categoría analítica explicativa de la manifestación diferenciada de la enfermedad en los grupos sociales y como ámbito de actuación y de definición de necesidades por los propios sujetos. El contexto de indignación creciente de diferentes grupos sociales con relación al régimen militar se entrecruzaba con el descontento provocado por la política de salud. En torno a esa superposición de agravios se conformó una plataforma general de democratización que congregó a las diversas agrupaciones de izquierda, sectores liberales, trabajadores y empresarios. En ese contexto de democratización amplia y de demanda de la deuda social acumulada, la plataforma político-ideológica de los salubristascolectivistas permitía el reconocimiento de la salud no sól o como un problema exclusivo de la medicina a ser resuelto con servicios de salud; por el contrario, había que definirla antes como un problema social a ser enfrentado en el espacio público de forma a que los servicios de salud no tuvieran que recurrir los resultados de las políticas económicas y sociales. En contra de las principales características de la intervención social del período militar - centralización financiera y control de decisiones en nivel federal, fragmentación institucional, ausencia de participación social y política, tendencia a privatización del aparato burocrático y favoritismo del sector privado en las relaciones público-privado -, la propuesta del SUS, que contempla la creación de un sistema nacional universal y integrado, con participación social en diferentes ámbitos de decisión, fue presentada como el medio necesario para convertir en realidad los anhelos de la sociedad de justicia social. En ese proceso, el concepto de salud colectiva fue la base teórico-científica a partir de la cual se concibió el SUS e se buscó instituir procedimentos sociales y políticos que permitieran revertir aúnque parcialmente una tendencia de medicalización de los problemas sociales. El ámbito técnico fue así, en cierta medida, desplazado hacia el ámbito político.

En México, también desde los años setenta, movidos por intereses díspares, algunos grupos sociales habían venido poniendo en tela de juicio los contenidos ideológicos del régimen priísta que tomaba expresión a través de un Estado interventor y organizador del desarrollo, al lado de otros, que reclamaban por democracia y por una mejor distribución de las ganancias de la industrialización. La nueva salud pública, con su discurso de la competencia y de la libre elección, de la participación responsable de los usuarios y de otros sectores sociales en asuntos referentes a la salud, se presentó como un punto de apoyo para los que abogaban un proyecto de renovación de la sociedad mexicana cuyo eje fue lo de crear una sociedad dirigida bajo la ideología del privado. En la sociedad de la eficiencia, basada en el uso de la investigación científica para producir informaciones y nuevos indicadores para orientar la toma de decisión y, así, solucionar la demanda reprimida, la nueva salud pública tomaba el lugar de los actores sociales, desplazando la respuesta del Estado del ámbito político para el técnico. A la vez, el mercado fue identificado y definido como un espacio perteneciente a la sociedad, productor de los recursos y servicios, capaz de resolver las necesidades en salud. Siendo así, el contexto de crisis económica y de reducción de gastos para el sector social fortaleció la salida económica racionalizadora y liberalizante, conectada a una reforma más administrativa que política del Estado, y propició la oportunidad para los neosalubristas, como un grupo coheso de expertos en gerencia de los sistemas de salud. En ese marco de reestructuración económica y política en que resolver los problemas de acceso a los servicios de salud era sobretodo un problema técnico y científico que dependía de dar a conocer los recursos y servicios existentes y garantizar el acceso según determinados parámetros que deberían conciliar equidad y racionalidad en los procesos de reforma, los neosalubristas ascendieron a la administración de las instituciones públicas de salud por medio de sus previas conexiones con la red de poder del PRI, para poner en marcha una estrategia de racionalización de los gastos en salud pública y liberalizar el mercado de servicios médicos. También aquí el concepto de nueva salud pública fue la base teórico-científica a partir de la cual se buscó instrumentalizar la reforma del sector salud y revertir una tendencia de uso político de las cuestiones sociales.

Por otro lado, en el caso de Brasil, Ios salubristas-colectivistas identificados con el pen- 
samiento de izquierda buscaron desempeñar el papel de portavoces de los grupos socialmente excluidos de los beneficios de la política de salud y, en nombre de esos grupos, promovieron alianzas con los sectores más sensibles a la cuestión social. También utilizaron de forma instrumental las oportunidades proporcionadas por las agencias internacionales sectoriales (OMS/OPS) y fundaciones privadas (Kellogg), además de intercambiar experiencias e ideas con Centros de Investigación sea de países de América Latina y de Centro América sea de Europa comprometidos con una perspectiva de carácter estructural en el combate de las desigualdades en salud. El fin del período militar y del surgimiento de actores con capacidad de representación hizo con que esos especialistas fuesen perdiendo su capacidad de dirigir el proceso de cambio que contribuyeron para desencadenar. Sin embargo, no perdieron la legitimidad política eideológica conquistada como profesionales del campo de la salud pública comprometidos con la promoción de políticas redistributivas en salud, además de haber paulatinamente ganado también legitimidad técnica.

De igual forma, en México, los neosalubristas identificados con Centros de Estados Unidos que participaron en la formulación de la agenda neo-liberal para el sector salud optaron por la anulación de la política en la solución de los problemas de salud dando preferencia a los argumentos técnicos. Al revés de debates abiertos, promovieron encuestas, la participación social fue interpretada como responsabilidad individual para con la salud, y el proceso de decisión continuó siendo interpretado como un ámbito de participación restricta. La anulación

\section{Agradecimentos}

Este artículo forma parte de los trabajos de investigación desarrollados, respectivamente, por Raquel Abrantes Pêgo, para su tesis de doctorado en El Colegio de Michoacán, México; y por Celia Almeida, en el proyecto de investigación La Reforma Sanitaria Brasilera: Actores, Regulación y Equidad, en la Escuela Nacional de Salud Pública de la Fundación Oswaldo Cruz (ENSP/ FIOCRUZ), Brasil. Se agradece al Kellogg Institute for International Studies de la Universidad de Notre Dame, que proporcionó el ambiente académico y los recursos de investigación necesarios para completar el trabajo durante la estancia de Raquel Abrantes como Guest Scholar de la institución, así como el apoyo del Instituto Nacional de Salud Pública de M éxico. de la política se convirtió en la política de los neosalubristas. También obtuvieron el apoyo de las agencias internacionales y de fundaciones privadas que compartían de sus propósitos y ideologías, además de haber conseguido formarse técnicamente en los instrumentos elaborados y difundidos por esas agencias. Y fue por medio de esas estrategias que lograron conquistar la legitimidad ideológica y técnica junto a los grupos sociales que dan prioridad a la prudencia y a la seguridad financiera en la solución de las desigualdades en salud y que están interesados en estimular al mercado como ámbito de creación de riqueza y de desarrollo tecnológico en salud.

En resumen, hacer estos paralelos y situar el proyecto de la salud colectiva y de la nueva salud pública en su contexto es importante ya que nos permite afirmar que, en ambos casos, los especialistas no sólo tomaron opciones, como estuvieron comprometidos con determinadas fuerzas políticas y económicas articuladas a ciertos grupos sociales. También porque la salud colectiva y la nueva salud pública son expresiones de un viejo confronto de ideas con relación a cómo enfrentar la desigualdad social que está inextricablemente entremezclada con las desigualdades frente a la enfermedad y a la muerte y, más específicamente, como afrontarlas a través de los sistemas de salud. De ahí nuestro esfuerzo en ubicar estos dos distintos proyectos técnico-científicos y políticos en sus respectivos contextos sociales y políticos y en las relaciones de conflicto propias del sector salud, de forma a explicitar sus bases de legitimación, tanto instrumental como ideológica, que justifican propuestas técnico-normativas distintas.

\section{Bibliografía}

ALMEIDA, C. M., 1995. As Reformas Sanitárias nos Anos 80: Crise ou Transição? Tese de Doutorado, Rio de Janeiro: Escola Nacional de Saúde Pública, Fundação Oswaldo Cruz.

ALMEIDA, C. M., 1996. Os modelos de reforma sanitaria dos anos 80: Uma análise crítica. SaúdeeSociedade, 5:3-57.

ALMEIDA, C. M., 1999. Reforma do Estado e reforma de sistemas de saúde: Experiências internacionais e tendências de mudança. Ciência \& Saúde Coletiva, 4:263-286.

ALMEIDA, C. M., 2001. Reforma del Estado y reforma de sistemas de salud. Cuadernos Médico-Sociales, 79:27-58 
ALMEIDA, C. M.; TRAVASSOS, C.; PORTO, S. \& WARGAS, T. B. F., 1999. A Reforma Sanitária Brasileira: Em Busca da Eqüidade. Research in Public Health, Technical Report, Washington, DC: Pan American Health Organization.

BIRMAN, J., 1991. A physis da saúde coletiva. Physis, 1:16.

BRASI L, 1988. Constitui ção da República Federativa do Brasil. Brasília: Senado Federal.

CAM POS, G. W. S., 1998. A reforma sanitária necessária. In: Reforma Sanitária - Itália e Brasil (G. Berlinguer, S. F. Teixeira \& G. W. S. Campos, org.), pp. 179-194, São Paulo: Editora Hucitec/Centro Brasileiro de Estudos de Saúde.

COHN, A., 1989. Caminhos da reforma sanitaria. Lua Nova, 19:123-140.

DONNANGELO, M. C. F., 1975. Medicina eSociedade, São Paulo: Biblioteca Pioneira em Ciências Sociais.

ESCOREL, S., 1987. Reviravolta na Saúde: Origem e Articulação do Movimento Sanitário. Dissertação de Mestrado, Rio de Janeiro: Escola Nacional de Saúde Pública, Fundação Oswaldo Cruz.

ESCOREL, S., 1998. Reviravolta na Saúde: Origem e Articulação do Movimi ento Sanitário. Rio de Janeiro: Editora Fiocruz.

FAVARET, P. \& OLIVEIRA, P. J., 1989. A Universalização Excludente- Reflexões sobre as Tendências do Sistema de Saúde. Texto para Discussão 216. Rio de Janeiro: Instituto de Economia Industrial, Universidade Federal do Rio de Janeiro. (mimeo.)

FIORI, J. L., 1991. Democracia e Reformas: Equívocos, Obstáculos e Disjuntivas. Brasilia: Organização Pan-Americana da Saúde/ Organização Mundial da Saúde. (mimeo.)

FRENK, J., 1994. La Salud dela Población. Hacia una Nueva Salud Pública. México, DF: Fondo de Cultura, Secretaría de Educación Pública.

FUNSALUD (Fundación Mexicana para la Salud), 1987. Mensaje de Dr. Guillermo Soberón Acevedo. In: Segunda Asamblea General Ordinaria, Memoria, pp. 10-11, México, DF: FUNSALUD.

FUNSALUD (Fundación Mexicana para la Salud), 1993. El modelo FUNSALUD. Cuadernos Funsalud, 1.

FUNSALUD (Fundación Mexicana para la Salud), 1994. Economía y Salud - Propuesta para el Avance del Sistema de Salud en México. Informe Final. México, DF: FUNSALUD.

FUNSALUD (Fundación Mexicana para la Salud), 1995. El modelo Funsalud, experiencia de una década 1985-1995. Cuadernos Funsalud, 10:27.

FUNSALUD (Fundación Mexicana para la Salud), 1996. Salud - La Sociedad Civil Frente a Ios Desafíos Nacionales. México, DF: FUNSALUD.

LAURELL, A. C., 2001. Health reform in Mexico: The promotion of inequality. International Journal of Health Services, 31:291-321.

LOEWE, R., 1988. Desplazamiento de personal adiestrado en Salud Pública: Teoría para la acción. Revista Higiene, 38:3-4.

LOPEZ-ACUÑA, D., 1980. La Salud Desigual en MéxiCo. México, DF: Siglo Veintiuno.

LUZ, M. T., 1991. Notas sobre as políticas de saúde no Brasil de transição democrática - Anos 80. Physis, 1:77-96.
MACHADO, F. A., 1988. As possibilidades de controle social das políticas públicas. Revista deAdministração Pública, 22:32-49.

MARQUES-PEREIRA, J., 1994. La reducción de la intervención social del Estado, In: Democracias Posibles - El Desafío Latinoamericano (G. Couffignal, org.), pp. 227-246, México, DF: Fondo de Cultura Económica.

MEDICl, A. C., 1990. Financiamento e contenção de custos nas políticas de saúde: Tendências atuais e perspectivas futuras. Planejamento e Políticas Públicas, 4:83-98.

MERCER, H., 1984. Integración de servicios de salud, M éxico 1981-1983. Cuadernos Médico-Sociales, 31:26-43.

MULLER NETO, J. S., 1989. O município e o financiamento da saúde. Saúdeem Debate, 27:23-29.

MULLER NETO, J. S., 1991a. Políticas de saúde no Brasil: A descentralização e seus atores. Saúdeem Debate, 31:54-67.

MULLER NETO, J. S., 1991b. Descentralização e democracia: Tópicos para um debate. Saúdeem De bate, 33:33-40.

NUNES, E. D. (org.), 1985. As Ciências Sociais em Saúde na América Latina, Brasília: Organização Pan-Americana da Saúde/ Organização Mundial da Saúde.

PODER EJECUTIVO FEDERAL, 1996. Programa de Reforma del Sector Salud. México, DF: Secretaría de Salud.

SECRETARIA DE SALUD, 1987. El Centro de Investigación en Salud Pública. México, DF: Instituto Nacional de Salud Pública.

SOBERON, G., 1983. Hacia un Sistema Nacional de Salud. México, DF: Universidad Autónoma Metropolitana de México.

TEIXEIRA, S. M. F., 1987. O dilema reformista na reforma sanitária brasileira. Revista de Administração Pública, 21:94-115.

TEIXEIRA, S. M. F., 1989. Política de saúde na transição conservadora. Saúde em Debate, 26:42-53.

TEIXEIRA, S. M. F. \& MENDONÇA, M. H., 1989. Reforma Sanitária na Itália e no Brasil: Comparações. In: Reforma Sanitária - Em Busca de uma Teoria (S. M. Teixeira, org.), pp. 195-232, Rio de Janeiro: Cortez Editora/ ABRASCO.

TELLO, C., 1989. México: Informe sobrela Crisis (19821986). México, DF: Centro de Investigaciones en Humanidades, Universidad Nacional Autónoma de México.

van STRALEN, C., 1998. The Struggle Over a National Health Care System. The Movimento Sanitário and Health Policy Making in Brazil: 1960-1990. Utrecht: Universiteit van Utrecht.

WARMAN, A., 1994. La Política Social en México, 1989-1994 - Una Visión de la Modernización de México. México, DF: Fondo de Cultura Económica.

Recibido el 15 de octubre de 2001

Versión final presentada el 12 de noviembre de 2001

Aprobado el 17 de enero de 2002 